\title{
Methods of estimating the cost of traffic safety equipment's life cycle
}

\author{
Beata Grzyl $^{1}$, Adam Kristowski ${ }^{1}$, Kazimierz Jamroz ${ }^{1}$, Anna Gobis ${ }^{1}$ \\ ${ }^{1}$ Gdansk University of Technology, Faculty of Civil and Environmental Engineering, Gdansk, Poland
}

\begin{abstract}
In the article, the authors discuss the preliminary information necessary to determine the scope and direction of further research conducted within the project called "The influence of time and operating conditions on the durability and functionality of road safety elements". The main objective of the project is to develop the concept of a method for optimizing the life cycle costs of road safety devices. The authors draw attention to the close connection between the decisions taken at the design stage and expenses incurred in the course of maintenance and the use of road safety devices, present the specificity of road infrastructure in terms of life cycle costs, discuss the components of the costs and give examples of the LCC analysis applied to the concrete barrier.
\end{abstract}

\section{Introduction}

One of the key priorities of the EU's Europe 2020 strategy is sustainable development involving support for a resource-efficient, environmentally friendly and competitive economy. Many EU documents promoting sustainable development quote the Life Cycle Cost estimation as a basis for decision-making (LCC) [1]. It involves calculating the total cost of the product, item, facility and service, generated in the period from the acquisition of raw materials to waste management, taking into account the phases of design, installation, operation, maintenance, recycling or disposal [2].

\section{The purpose of research}

The cost of installation of road safety elements, their resilience and reliability depend on many factors, including: detailed technical design, quality and correct installation and the scope and capacity for maintenance and operation. To ensure that spending is rational, in terms of the life cycle cost of a road safety device, the above issues must be considered at the stage of planning and drafting. In many cases, the investor/purchaser analyses only the initial effort (assembling the device) and the technical parameters (expressed with better road safety and driving comfort) and ignores the costs of operation. It should be noted, however, that lower costs borne by the investor/purchaser at the stage of investment, in the long term, are likely to generate significant expenditure due to ongoing operation and maintenance of road safety devices.

\footnotetext{
* Corresponding author: beata.grzyl@,wilis.pg.gda.pl
} 
In the course of the research, identification and analysis will be conducted of major factors generating significant costs, which may be significantly reduced (at the stage of operation and maintenance). The work will outline the relationship between selected factors (e.g. kind of safety barrier, type of road, speed limits, type of collision, traffic, weather conditions, time of year), the scope of the damage and the number of repairs of road safety equipment and the cost of repair, renovations or replacement. Depending on the scope of the input data (e.g. in the form of historical data) in the LCC analysis, account will be taken of the average cost and time to repair and replace the road safety equipment including the impact of various factors (type of barrier, road type, type and scope of collision, frequency and extent of damage, the scope of conducted repair and replacement) as well as road users and social and economic cost.

\section{The specificity of road infrastructure and road safety devices}

Factors that have a decisive impact on the life cycle cost of road safety devices include: the type and nature of their work, traffic, weather conditions (climatic factors), the location and level of functionality. The fundamental problems associated with the operation of road safety devices which also have an impact on their life cycle cost include [3,4]:

- lack of qualifications and expertise of the contractors - regarding the specifics of road safety devices which results in errors in the installation, repair, reconstruction,

- failure to include in tendering procedures the need for uniform and compatible solutions (types) of devices on the adjacent road sections,

- difficulties with effective enforcement of the warranty of contract performance from the companies managing the specific road section,

- companies responsible for maintaining the road section lack detailed knowledge on the conditions of operation, maintenance, repair, restoration of road safety devices,

- no possibility of a quick exchange of a barrier for another of the same type, as a result other spare parts are used (i.e. from other manufacturers) which increases the probability of the barrier losing its functional parameters.

The main expenditure of the life cycle and road infrastructure costs are borne by road managers. This is related to maintenance and operation (often estimated over a specific period of, e.g. 25 years).

In order to determine the optimal life cycle cost of road infrastructure, costs should be estimated which are incurred by the individual user (e.g. disruption caused by maintenance works, removal of consequences of road collisions and accidents), social losses (e.g. the deterioration of the health and quality of life of local residents) or the impact on the environment (air pollution and noise) [5].

Many road managers in the world in order to increase the efficiency of the expenditure and reduce the costs of maintenance and use of roads and infrastructure and to maximize socio-economic benefits, have developed their own models of LCC analysis. There are different types of models - from simple models taking into account only the cost of supplies, to more complex involving social costs. One of the methods for assessing the design of road construction by using analysis of the annual cost is given in [6]. The publication highlights the difficulties associated with determining the costs of management of road infrastructure and the lack of knowledge of the designers on the scope of maintenance.

In [7] models are analysed for calculating life-cycle costs developed by road managers: COMPARE (United Kingdom), QUEWZ (Australia), Whole Life Costing System (USA) and Highway Design and Management (HDM I-IV). These models, however, are used primarily in the design and construction of roads and pavements. The authors presenting these models $[3,4,6-8]$ pay attention to restrictions in calculating the life cycle costs. The functionality management of road safety devices in terms of the cost of their life cycle. The usability 
(usefulness) of road traffic safety equipment is expressed mainly with maintaining the continuity of its operations. This includes ensuring that road users can rely on the relevant quality parameters of the transmission of information and vehicle safety, etc. over a specific period. The functionality management of the road safety equipment is based on maintaining a high degree of its readiness for operation, as well as rapid removal of damage or failure [8].

\section{The components of the life cycle costs of road safety devices}

Device manufacturers use LCC road safety analysis in order to optimize the cost of the life cycle, taking into account safety, degree of functional failure, frequency of maintenance, etc. In practice, however, in many cases the costs incurred in the full life cycle of the device are omitted, and investment decisions are made based on short-term criteria. This causes the negative consequences of financial but also environmental nature (the need for early disposal of waste). Due to the fact that the resilience of some road safety equipment dates back 1525-30 years, and the costs associated with their operation and maintenance far outweigh the initial outlay, the criterion of the lowest price should not be the sole determinant in making an investment decision. The costs generated in subsequent stages of the life cycle of the road safety device include:

- the concept and definition (includes the cost of market research, analysis, concept, defining the requirements for the product),

- the design and development (includes the cost of the documentation design, prototype production, software, quality management),

- production (includes manufacturing costs, delivery to the market - loading, transport),

- installation - assembly,

- the use and handling (includes the cost of repairs, maintenance, spare parts, technical support, incurred over a given time of the device's operation),

- decommissioning (includes the cost of dismantling, recycling or disposal).

The total costs incurred in the life cycle of a road safety device can also be divided into [8] the cost of acquisition and ownership. The acquisition costs primarily include costs of investment - the purchase of equipment (i.e. the design and manufacturing) and its installation [9]. Ownership costs include operating costs, maintenance, scheduled maintenance, troubleshooting, but also the environmental, social and decommissioning costs. Typically, the cost of ownership outweigh the costs of acquisition.

In relation to the total cost incurred during the life cycle of road safety devices, another possible division is into [8]: user and manager costs. The costs incurred by managers include fees associated with the maintenance and use of road safety equipment: repair, replacement, maintenance of individual items, interventions. In practice, a big problem is determining the value of a random occurrence of events (accidents, collisions) and frequent lack of information about the events. User costs (also included in the cost of ownership) will be borne by an individual or group of road users and include losses resulting from the occurrence of road incidents. These include the costs of incidents, accidents, injuries and fatalities, but also the cost of wasted time of road users, repair of motor vehicles and environment protection $[8,10,11]$.

The essential factors to be taken into account when determining the costs of maintenance and use of road safety equipment include [8,10,11]: the device type, period (winter, summer) in which damage/destruction of barrier occur, road conditions, location of the barrier, road type, current speed limit on the road, the distance between the barriers and the edge of the lane, number of lanes on the road. The amount of the costs associated with the repair also determines the scope of repair, the extent of the damage caused by the impact of the vehicle and the amount of granted compensation. 


\section{The procedure for conducting the LCC analysis}

The process of LCC analysis can be divided into several key stages. An important element of estimating the life cycle costs of road safety devices is to define the actions that have an impact on the reduction or increase in costs and to establish the correlation between them. An important aspect of the analysis are cost data collected from road managers and those responsible for maintenance of road (when such information is collected). A significant element of the LCC analysis is also relevant to the lifetime of the road safety device (15-2530 years) and the amount of the discount rate. Formulated in this way, input data can be processed using a specific calculation model.

\subsection{Methods of LCC analysis. An example of life-cycle cost of a road barrier}

There are two main groups of LCC analysis methods [1]:

- simple, uncomplicated comparisons designed to select the optimal variant of the process without discounting,

- complex, including discounted cash flow analysis for the period from installation to withdrawal from use, integrating the different elements of the costs incurred during the life cycle (such as maintenance, operation, repair, dismantling).

The selection of the appropriate LCC method depends on the nature, scope and complexity of the project. Methods that can be used to estimate the components of the life cycle cost of road safety devices are [1]:

- the engineering method to estimate the cost (direct testing of the product, component after component),

- the method of estimating the cost by analogy (an estimate based on experience gained from similar products or technologies),

- parametric cost estimation method (the use of parameters and variables to develop according to estimating cost).

The authors present a sample calculation cost of concrete barriers life-cycle. Calculations performed by estimating the cost by analogy using data and information are contained in [12]. In order to perform an LCC analysis assumptions are taken as shown in Table 1.

Table 1. Assumptions used for the LCC analysis. source: own study based on [12].

\begin{tabular}{|l|l|}
\hline Data & Value \\
\hline Type of road safety device & $\begin{array}{l}\text { The concrete barrier prefabricated } \\
\text { outside the place of assembly }\end{array}$ \\
\hline $\begin{array}{l}\text { The average annual cost of use and maintenance } \\
\text { (including repairs and routine maintenance) }\end{array}$ & $0.62 \mathrm{PLN} / \mathrm{m} /$ year \\
\hline The cost of barrier installation & $298.14 \mathrm{PLN} / \mathrm{m}$ gross [13] \\
\hline The assumed discount rate & $5 \%$ \\
\hline Adopted lifetime & 15 years \\
\hline The total LCC life cycle cost & 4273.29 PLN \\
\hline
\end{tabular}

This LCC analysis indicates that the cost of operation and maintenance of concrete barriers within the given period and adopted output data is more than 14 times higher than the initial effort. 


\subsection{Restrictions on the LCC application}

LCC analysis provides a new approach more widely used, for example, in the process of designing and making an investment decision on the choice of road safety devices with certain characteristics. In practice, however, there are difficulties and constraints characteristic of many techniques and utility costs. The most important ones are presented by the authors later in the article.

1. The LCC analysis method is not rigorous, as a result it can generate different results. This is due to the fact that the costs included in the analysis are only approximate (especially those assigned to the phase of the operation, maintenance and decommissioning). The analysis requires a lot of input data (e.g. difficult to obtain from road managers and maintenance companies).

2. In practice, designers lack knowledge on the technology of repairs to road safety devices and the associated costs. In addition, estimating the costs at the social, administrative and economic design stage is a difficult task.

3. There are no reliable data on the maintenance and use of road safety devices due to the fact that the majority of road managers do not have a suitable method for systematic data collection. There are no accurate models of road structure aging to take account of progress of civilization (including increasing annual volumes of traffic) [11] or to consider changes in the cost calculation.

\section{Conclusions}

The analysis of the literature and the authors' own experience justify the conclusions, statements and recommendations stated below.

1. The use of LCC at the concept stage, when defining and designing road safety devices is a great opportunity to reduce costs over the life cycle. Due to the lack of information regarding costs of operation and liquidation of a given type of road safety device, further research conducted by the authors includes creating a database of road maintenance costs on the basis of information obtained from road managers and entities responsible for carrying out maintenance work on roads.

2. As indicated in practice one of the reasons for increasing the operating costs of road safety devices is that road managers and maintenance companies apply the old technology and incompatible solutions. If incorrectly selected, the technology increases the cost of repairs and traffic congestion. The rational solution is to use a technology that offers a low replacement cost. It is therefore necessary to analyse the use of barriers with different initial outlays and the cost of repair and maintenance.

3. Despite numerous constraints (such as determining the individual components of costs requires conducting field, laboratory and simulation research), LCC analysis can be applied to assess the effectiveness of variants of the purchase of new equipment or upgrading existing road safety. It provides transparent information about the possible consequences of solutions, including, among others, cost, lifetime and reliability of the road safety device parameter.

\section{Acknowledgements}

Research conducted under project implemented within RID programme, funded by the Polish National Centre for Research and Development and the General Directorate for National Roads and Motorways in Poland, for the years 2016-2019. 


\section{References}

1. PN-EN 63300-3-3 Zarządzanie niezawodnością część 3-3: Przewodnik zastosowań. Szacowanie kosztu cyklu życia (2006)

2. Directive 2009/125/EC of the European Parliament and of the Council of 21 October 2009 establishing a framework for the setting of ecodesign requirements for energyrelated products (2009)

3. Bagiński G., Problemy utrzymania drogowych środków brd, in: XI Int. Road Saf. Semin. GAMBIT 2016, (Gdansk, 2016)

4. K. Jamroz, Method of risk management in highway engineering. Metoda zarządzania ryzykiem w inżynierii drogowej (Gdansk University of Technology, Gdansk, 2011)

5. Mainline - Maintenance, renewal and improvement of rail transport infrastructure to reduce economic and environmental impacts, 7 FP EU (Brussels, n.d.)

6. U. Olsson, Projektering med hänsyn till drift och underhåll. Infrastructure design with regard to maintenance and operation. Report No.1983:25 (Construction Research Council, Stockholm, 1983)

7. A. Huvstig, "Whole Life Cost," in: 8th Int. Symp. Concr. Roads, Lisbon, Sept. 1316, Proceedings, Theme III, pp. 43-51 (1998)

8. H. Karim, Improved Road Design for Future Maintenance - Analysis of Road Barrier Repair Costs, Royal Institute of Technology, Stockholm, 2008

9. B. Grzyl, A. Kristowski, A calculation proposal of labour time input when concreting in difficult atmospheric conditions, Czas. Tech. Bud. Zesz. 2-B. (2014)

10. H. Karim, Road Design for Future Maintenance - Life-cycle Cost Analyses for Road Barriers, (2011)

11. H. Karim, R. Magnusson, K. Natanaelsson, Life-Cycle Cost Analyses for Road Barriers, J. Transp. Eng. 138 pp. 830-851 (2012)

12. S.A. Cooner, Y.K. Rathod, D.C. Alberson, R.P. Bligh, S.E. Ranft, D. Sun, Performance Evaluation Of Cable Median Barrier Systems In Texas. Report No. FHWA/TX-09/0-5609-1. Available: http://tti.tamu.edu/documents/0-5609-1.pdf (2009)

13. www.drogowe.com.pl, (n.d.) 